\title{
Active immunotherapy for mouse breast cancer with irradiated whole-cell vaccine expressing VEGFR2
}

\author{
HENG-XIU YAN $^{1,2}$, PING CHENG $^{1}$, HAI-YAN WEI ${ }^{1}$, GUO-BO SHEN ${ }^{1}$, \\ LI-XIN FU ${ }^{2}$, JIE NI ${ }^{1}$, YANG WU ${ }^{1}$ and YU-QUAN WEI ${ }^{1}$ \\ ${ }^{1}$ State Key Laboratory of Biotherapy and Cancer Center, West China Hospital, \\ West China Medical School, Sichuan University, Chengdu; ${ }^{2}$ College of Life Science and Technology, \\ Southwest University for Nationalities, Chengdu, Sichuan, P.R. China
}

Received October 12, 2012; Accepted November 28, 2012

DOI: $10.3892 /$ or.2013.2282

\begin{abstract}
As tumor-associated antigens are not well characterized for the majority of human tumors, polyvalent vaccines prepared with whole-tumor antigens are an attractive approach for tumor vaccination. Vascular endothelial growth factor receptor-2 (VEGFR2), as a model antigen with which to explore the feasibility of immunotherapy, has shown great promise as a tumor vaccine. However, the efficacy of immunotherapy is often not ideal when used alone. In this study, we explored the therapeutic efficacy of an irradiated AdVEGFR2-infected cell vaccine-based immunotherapy in the weakly immunogenic and highly metastatic 4T1 murine mammary cancer model. An adenovirus encoding the VEGFR2 gene (AdVEGFR2) was constructed. Lethally irradiated, virus-infected 4T1 cells were used as vaccines. Vaccination with lethally irradiated AdVEGFR2-infected 4T1 cells inhibited subsequent tumor growth and pulmonary metastasis compared with challenge inoculations. Angiogenesis was inhibited, and the number of $\mathrm{CD}^{+} \mathrm{T}$ lymphocytes was increased within the tumors. Antitumor activity was also caused by the adoptive transfer of isolated spleen lymphocytes. In vitro, the expression of HMGB1 and HSP70 in the AdVEGFR2-infected 4T1 cells was increased, and was involved in the activation of tumor antigen-specific T-cell immunity. Our results indicate that the immunotherapy based on irradiated AdVEGFR2-infected whole-cancer cell vaccines may be a potentially effective strategy for 4T1 cancer treatment.
\end{abstract}

\section{Introduction}

Whole-cell vaccines are a method for providing target antigens. In this approach, the whole-tumor cell is the source

Correspondence to: Professor Yang Wu, State Key Laboratory of Biotherapy and Cancer Center, West China Hospital, West China Medical School, Sichuan University, No. 17, 3rd Section Ren Ming Nan Road, Chengdu, Sichuan 610041, P.R. China

E-mail: stillwy@163.com

Key words: whole-cell vaccine, VEGFR2, immunotherapy, breast cancer of immunogens with which to induce an antitumor immune response. The advantage of using whole-tumor cell vaccine is that a broad array of tumor-associated antigens (TAAs) is represented, thereby minimizing immune escape. As whole proteins are present, there are no HLA restrictions on who can receive the vaccine. However, it is not ideal to use live pathogens as vaccines due to safety concerns. Killed but maintained immunogenicity via $\gamma$-irradiation has been reported to have the benefit of vaccines to induce an appropriate immune response without the issue of pathogen replication in the host (1-5). Meanwhile, the weak immunogenicity of many tumors also represents a barrier to the effective induction of antitumor immunity. Reportedly, cancer cells or other bystander cells included in the vaccine are transfected with vectors containing genes that express potent immunostimulating proteins or cytokines, including B7.1 (CD80), GM-CSF and CCL21 (6-11).

Vascular endothelial growth factor receptor-2 (VEGFR2) is an important receptor responsible for the angiogenic activity of VEGF $(12,13)$. Overexpression of VEGFR2 is found on activated endothelial cells of newly formed vessels and is strongly associated with invasion and metastasis in many types of cancer (14-16). In addition, it has been reported that the inhibition of tumor growth and metastasis in many animal models has been achieved by various techniques that disrupt or neutralize the functions of either VEGF or VEGFR-2 (17-19). In our previous research, a xenogeneic homologous VEGFR2 protein vaccine (qVEGFR) effectively inhibited the tumor growth in LL/2 Lewis lung carcinoma, CT26 colon carcinoma, and Meth A fibrosarcoma models (20). It is, thus, clear that the breaking of the immune tolerance against VEGFR2 of autologous angiogenic endothelial cells is an effective pathway for cancer therapy with active immunity.

In the present study, we explored the therapeutic efficacy of an irradiated AdVEGFR2-infected autologous whole-cell tumor vaccination in the weakly immunogenic and highly metastatic 4T1 murine mammary cancer model. Moreover, we also further discussed its possible mechanism.

\section{Materials and methods}

Cell lines and mice. The 293A (human embryonic kidney) and 4T1 cell lines were obtained from the American Type Culture 
Collection (Manassas, VA, USA). Cells were cultured in DMEM supplemented with $10 \%$ fetal bovine serum (FBS) and $10 \mu \mathrm{g} / \mathrm{ml}$ gentamicin sulfate, maintained in a $37^{\circ} \mathrm{C}$ incubator with a humidified $5 \% \mathrm{CO}_{2}$ atmosphere. Six- to 8-week-old female BALB/c mice were obtained from the Laboratory Animal Center of Sichuan University and maintained in pathogen-free conditions. All procedures were approved by the institute's Animal Care and Use Committee.

Construction of recombinant adenoviral vectors. A recombinant adenovirus carrying the VEGFR2 gene (AdVEGFR2) was constructed by use of the AdEasy system from Qbiogene, Inc., according to the procedure provided by the manufacturer. The recombinant adenovirus without a foreign gene (Adnull) served as a control. All virus particles were amplified in HEK 293A cells and titrated as $\mathrm{PFU} / \mathrm{ml}$ and stored at $-80^{\circ} \mathrm{C}$.

Preparation of whole-cell vaccines. To vaccinate mice, 4T1 cells were infected by AdVEGFR2 or Adnull (control) at a MOI of 100 in serum-free RPMI-1640. Cells were incubated at $37^{\circ} \mathrm{C}$ for $48 \mathrm{~h}$. Infected cells and uninfected $4 \mathrm{~T} 1$ cells were irradiated with 100 Gy and subsequently injected s.c. into the flanks of the mice.

Breast tumor model and immunotherapy. 4T1 breast cancer models were established in BALB/c mice. Six mice in each group were challenged with $1 \times 10^{6} 4 \mathrm{~T} 1$ cells s.c.in the right flank. For vaccination, 4T1 cells were infected with AdVEGFR2 or Adnull or were uninfected, and then irradiated with $100 \mathrm{~Gy}$ of $\mathrm{X}$-rays. Irradiated cells were washed extensively with PBS and vaccination was carried out by s.c. injection of $1 \times 10^{6}$ cells, 3 times, on Days 7,21 and 28 in the left flank of mice after tumor cell inoculation. Additional control animals were injected with $0.9 \% \mathrm{NaCl}$ solution. Thus, mice were divided into 4 groups: the irradiated AdVEGFR2-infected 4T1 cell-treated group (4T1-AdVEGFR2 group), the irradiated Adnull-infected 4T1 cell-treated group (4T1-Adnull group), the irradiated 4T1 cell-treated group (4T1 group) and the saline-treated group (NS group). Tumor dimensions were measured with calipers every 3 days, and the tumor volume (V) was calculated according to the following formula: $\mathrm{V}=0.52 \mathrm{x}$ length $\mathrm{x}$ width ${ }^{2}$.

Adoptive transfer in vivo. Ten mice in each group were immunized with $1 \times 10^{6}$ irradiated AdVEGFR2-infected 4T1 cells, Adnull-infected 4T1 cells, 4T1 cells or NS s.c. in the right flank 3 times on Days 1, 14 and 28. Sera derived from the mice on Day 7 after the third immunization were adoptively and intraperitoneally transferred 1 day (100 $\mu \mathrm{l}$ serum/mouse) before mice were challenged with $1 \times 10^{6} 4 \mathrm{~T} 1$ cells s.c. in the right flank and then were treated once per day for 10 days. In addition, isolated spleen lymphocytes from the immunized mice were adoptively and intravenously transferred $\left(1 \times 10^{6}\right.$ cells/100 $\mu \mathrm{l} /$ mouse) and were then treated twice per week for 2 weeks. Tumor dimensions were measured with calipers every 4 days for 29 days, and tumor volume (V) was calculated according to the following formula: $\mathrm{V}=0.52 \mathrm{x}$ length $\mathrm{x}$ width ${ }^{2}$.

Histological analysis. Tumors from each group were embedded in paraffin, and sections $(3-5 \mu \mathrm{m})$ were immunohistochemically stained to determine the infiltration of lymphocytes and quantify the microvessel density in the tumor tissue using rat anti-mouse CD4 antibody, rat anti-mouse CD8 antibody and rabbit anti-mouse CD31 antibody (Abcam, Inc.). Vascular density was quantified by counting the number of microvessels per high power field. Images were acquired using an Olympus BX60 microscope.

Quantitative assessment of apoptosis. Tumor species were prepared as previously described (21). The presence of apoptotic cells within the tumor sections was determined using the In Situ Cell Death Detection kit (DeadEnd ${ }^{\mathrm{TM}}$ Fluorometric TUNEL System, Promega, Madison, WI, USA), according to the manufacturer's protocol. In tissue sections, five high power fields were randomly chosen and analyzed. The apoptotic index (AI) was defined as follows: AI $(\%)=100 \mathrm{x}$ apoptotic cells/total tumor cells. Images were acquired using a LEICA DM2500 microscope.

Western blot analysis. The 293A cells infected with AdVEGFR2 or Adnull for $48 \mathrm{~h}$ were lysed to analysis the expression of VEGFR2 using rabbit anti-mouse VEGFR2 antibody (Abcam). 4T1 cells infected with AdVEGFR2 or Adnull for $48 \mathrm{~h}$ and uninfected 4T1 cells were irratiated with $100 \mathrm{~Gy}$, and their lysates were subjected to western blot analysis with rabbit anti-mouse HMGB1 and HSP70 antibodies.

FCAS. For FACS analysis, we prepared single-cell suspensions of tumors from 4T1-AdVEGFR2-treated or 4T1-Adnulltreated mice. Briefly, tumors were minced using a razor blade and digested with collagenase I for $30 \mathrm{~min}$ at $37^{\circ} \mathrm{C}$. For extracellular staining of immune markers, $5 \times 10^{5}$ of freshly prepared cells were stained with PE CD4 and FITC CD8. Fluorescence data were collected on FACScalibur and analyzed using cell quest software (BD Biosciences).

ELISA. For ELISA, 96-well plates were coated with 4T1 cells $\left(1 \times 10^{4}\right.$ cells/well) in $10 \%$ RPMI-1640 overnight at $4^{\circ} \mathrm{C}$. Plates were washed with PBST $(0.05 \%$ Tween 20 in PBS) and were fixed in $10 \%$ formalin for $15 \mathrm{~min}$ at room temperature. Then, plates were washed with $\mathrm{ddH}_{2} \mathrm{O}$ and blocked for $1 \mathrm{~h}$ at $37^{\circ} \mathrm{C}$ with $200 \mu \mathrm{l} /$ well $1 \%$ bovine serum albumin (BSA) in PBST. Mouse sera from treated mice diluted serially in PBS were added for $2 \mathrm{~h}$ at $37^{\circ} \mathrm{C}$, followed by a dilution of anti-mouse immunoglobulin $\mathrm{G}(\mathrm{Ig} \mathrm{G})$ subclass or anti-IgM or anti-IgA antibody conjugated to alkaline phosphatase. Enzyme activity was measured using an enzyme-linked immunosorbent assay (ELISA) reader (Multiskan MK3).

Statistical analysis. SPSS 16.0 was used for statistical analysis. Data are expressed as means \pm SD. The statistical analysis in all the experiments was performed using one-way analysis of variance (ANOVA). P-value $<0.05$ was considered to indicate a statistically significant result.

\section{Results}

Construction of the recombinant VEGFR2-expressing adenovirus. Positive clones were confirmed by restriction enzyme analysis and DNA sequencing. The PacI-digested pAdVEGFR2 plasmid was transfected into 293 cells. At the 
A

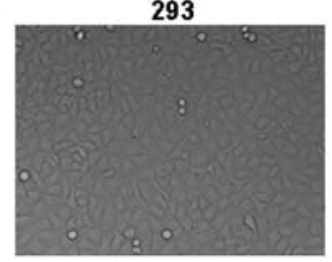

293-AdVEGFR2

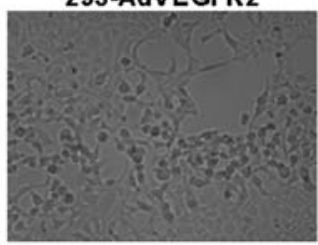

B

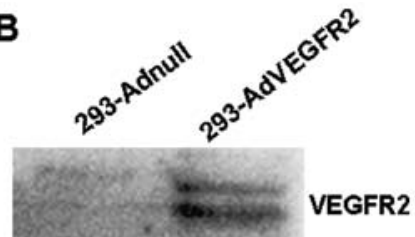

Figure 1. Packaging of AdVEGFR2 and the expression of VEGFR2 in 293 cells. (A) The images show 293 cells transfected with pAdVEGFR2 as they undergo CPE on Days 8-10 post-transfection. (B) Expression of VEGFR2 in AdVEGFR2-infected and Adnull-infected 293 cells. Data are representative of two independent experiments.

A

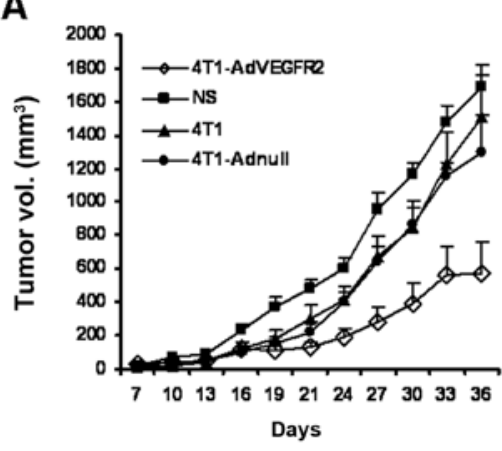

B

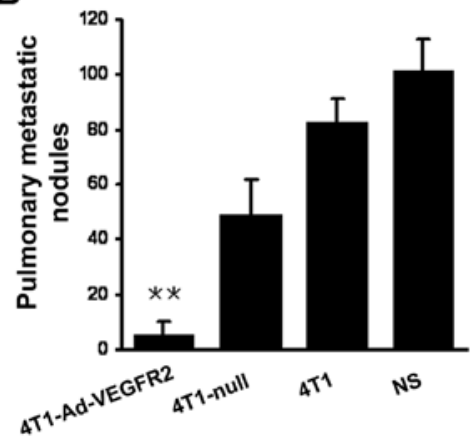

Figure 2. Induction of therapeutic antitumor immunity. Mice ( $\mathrm{n}=6$ in each group) were treated s.c. with $1 \times 10^{6}$ irradiated $4 \mathrm{~T} 1$ cells infected with AdVEGFR 2 or Adnull or were uninfected and treated with $0.9 \% \mathrm{NaCl}$ solution after challenged with $1 \times 10^{6} 4 \mathrm{~T} 1$ cells s.c. on Days 7,21 and 28 for the induction of the therapeutic antitumor immunity. (A) Tumor size of each mouse was monitored every 3 days. The differences between the 4T1-AdVEGFR2-treated group and the control groups were significant $(\mathrm{P}<0.05)$ starting on Day 24. (B) Pulmonary metastatic nodules were counted. The differences between the 4T1-AdVEGFR2treated group and the control groups were significant $(\mathrm{P}<0.001)$. Data are representative of two independent experiments. ${ }^{* *} \mathrm{P}<0.001$.

early stage, cells producing the adenovirus first appear as patches of rounding, dying cells. As the infection proceeded, cells containing the viral particles lysed and infected neighboring cells. A plaque began to form. On Days 8-10 posttransfection, the infected neighboring cells lysed, forming a plaque that was clearly visible (Fig. 1A). The expression of VEGFR2 in the AdVEGFR2-infected 293 cells was detected using western blotting (Fig. 1B).

Induction of therapeutic antitumor immunity. We tested the therapeutic efficacy of lethally irradiated AdVEGFR2infected 4T1 cells used as vaccines in established tumors. We treated the mice on Day 7 after 4T1 cell inoculation, when the tumors were visible and palpable. Following treatment with the vaccine 3 times on Days 7,21 and 28, the size of the tumor nodes in the 4T1-AdVEGFR2-treated group was significantly smaller in comparison with those in the control groups starting on Day $24(\mathrm{P}<0.05)$ (Fig. 2A). Furthermore, lung metastatic nodules of mice sacrificed at the termination of the experiment were counted under a dissecting microscope. Lung metastatic nodules in the 4T1-AdVEGFR2-treated group were nearly absent compared with the control groups $(\mathrm{P}<0.05)$ (Fig. 2B). We monitored the mice treated with the vaccines every 3 days throughout the entire experiment. No severe toxic effects were observed in terms of gross measures, such as weight loss, ruffling of fur and feeding. Thus, the therapy with the irradiated AdVEGFR2-infected cell vaccine not only inhibited the growth of the implanted tumors, but also restrained tumor metastasis.
Induction of tumor apoptosis and inhibition of tumor angiogenesis. To explore the role of the irradiated AdVEGFR2-infected 4T1 cell vaccine on the apoptosis of tumor cells, TUNEL assay of tumor sections was performed. As shown in Fig. 3A, within a similar high-power field, more apoptotic cells were noted in the tumor tissues from the 4T1-AdVEGFR2-treated mice, and the differences were significant compared with those of the control groups $(\mathrm{P}<0.001)$ (Fig. 3B). As VEGFR2 is closely related to tumor angiogenic blood vessels, we hypothesized that the therapy with the irradiated AdVEGFR2-infected 4T1 cell vaccine would act partly via an antiangiogenic mechanism to promote tumor regression. Thus, we investigated the microvessel density in the tumor sections by immunohistochemistry using an antibody specific for CD31. Results showed that the 4T1 tumor regression after irradiated AdVEGFR2infected $4 \mathrm{~T} 1$ cell vaccine treatment was accompanied by a corresponding decrease in microvessel density compared with the controls $(\mathrm{P}<0.001)$ (Fig. 3C).

Cellular and humoral immune response in irradiated AdVEGFR2-infected $4 T 1$ cell vaccine-induced antitumor activity. To explore the possible mechanism through which the antitumor activity was induced by the irradiated AdVEGFR2infected 4T1 cell vaccine, anti-CD4 and anti-CD8 monoclonal antibodies were used in immunohistochemical staining and FACS. As shown in Fig. 4A, the infiltration of $\mathrm{CD}^{+}$ and $\mathrm{CD}^{+} \mathrm{T}$ lymphocytes was apparently increased in the 4T1-AdVEGFR2-treated group. Results from FACS indicated the number of $\mathrm{CD}^{+}$lymphocytes was increased by $63.8 \%$ and 
A

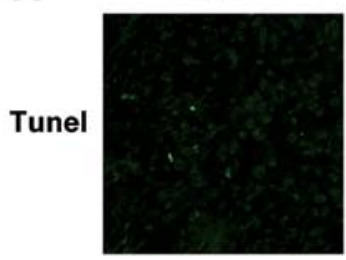

CD31

B

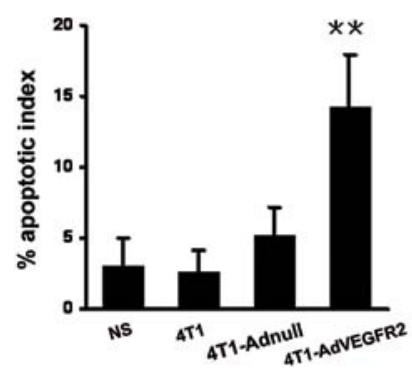

$4 \mathrm{T1}$
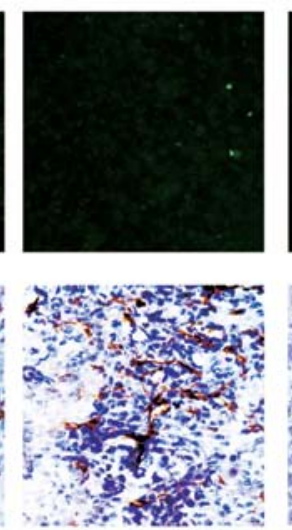

4T1-Adnull
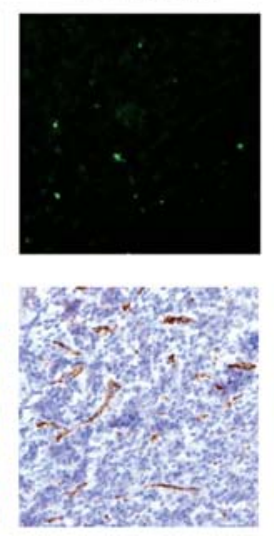

\section{T1-AdVEGFR2}
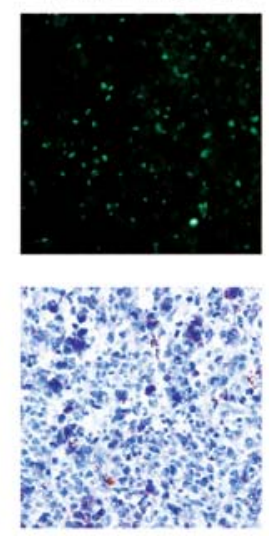

C

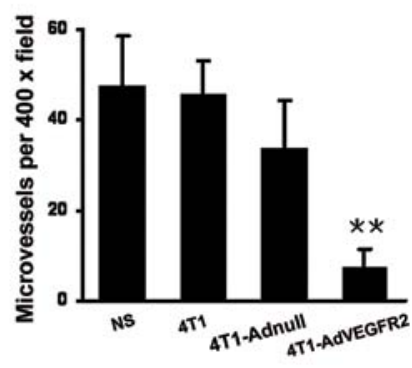

Figure 3. Histological and histomorphometric analysis. (A) Top panel: TUNEL assay revealed that 4T1-AdVEGFR2 induced a significant enhancement in the number of apoptotic cells versus the controls (magnification, x200). Bottom panel: Vascularization within tumors was detected by an antibody to CD31 (magnification, x100). Shown are representative sections from each group. (B) The percentage of apoptosis in each group. The number of apoptotic tumor cells in the tumor sections from the 4T1-AdVEGFR2-treated group was increased compared with the control groups ( $<<0.001$, respectively). (C) CD31-positive microvessels in each group. Vascular density was quantified by counting the number of microvessels per high power field. There was a decrease in the density of CD31-positive microvessels in the 4T1-AdVEGFR2-treated group $(\mathrm{P}<0.001)$. Values are expressed as the means $\pm \mathrm{SD}$. ${ }^{* *} \mathrm{P}<0.001$.

A

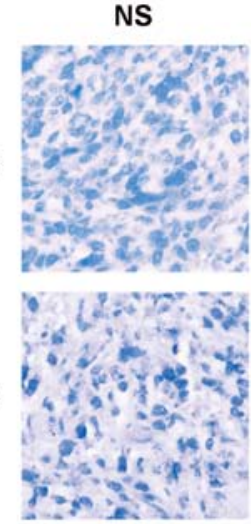

B

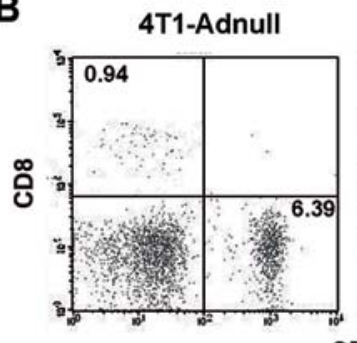

4T1

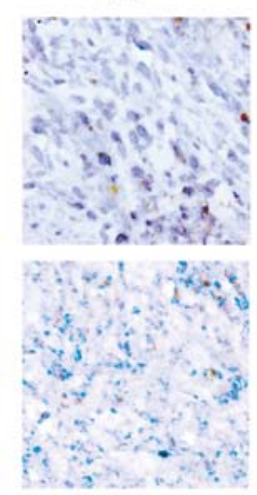

4T1-AdVEGFR

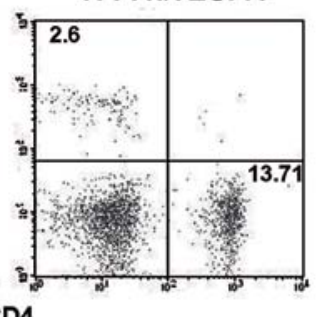

4T1-Adnull

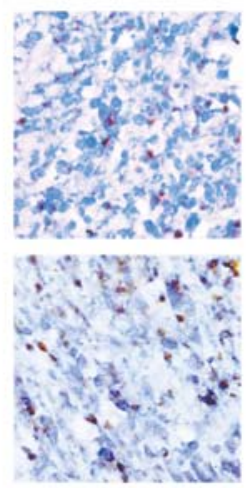

4T1-AdVEGFR2

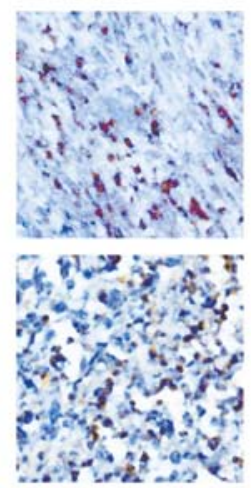

C



Figure 4. Analysis of the cellular and humoral immune response. (A) Immunohistochemical staining of CD4 and CD8 was used to detect lymphocyte infiltration into tumors in situ. Representative staining at $\mathrm{x} 200$ is shown. (B) The number of $\mathrm{CD} 8^{+}$and $\mathrm{CD} 4^{+}$cells were found by FACS to be increased in the 4T1-AdVEGFR2-treated group compared with the 4T1-Adnull-treated group. Numerals indicate the percentage of CD8 ${ }^{+}$or $\mathrm{CD} 4^{+}$cells within the total cell gate. A representative flow cytometric analysis is shown. (C) Autoantibodies against 4T1 cells were detected by ELISA. The differences between the 4T1-AdVEGFR2-treated group and the control groups were significant $(\mathrm{P}<0.001)$. Data are representative of two independent experiments. ** $\mathrm{P}<0.001$. 
A

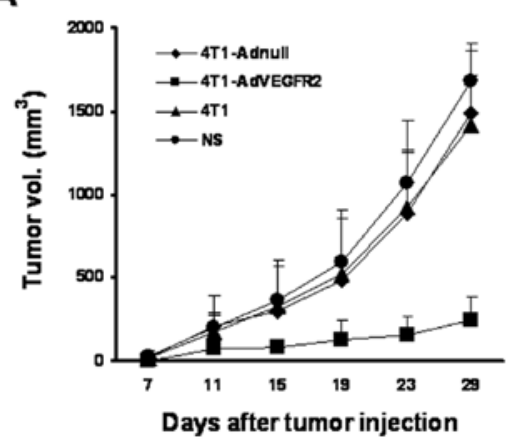

B

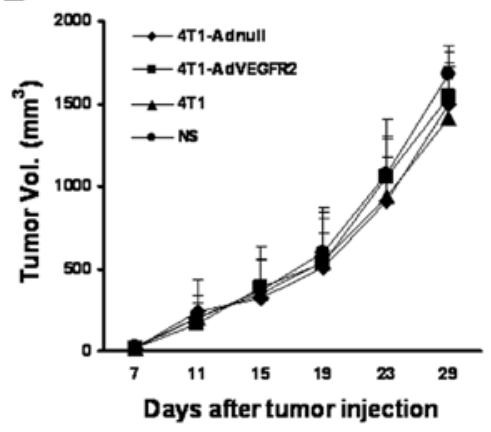

Figure 5. Antitumor effect by the adoptive transfer of lymphocytes in vivo. The protective antitumor effect against $4 \mathrm{~T} 1$ cells was tested with isolated lymphocytes and sera from mice immunized with 4T1-AdVEGFR2, 4T1-Adnull, 4T1 or NS. (A) Treatment with lymphocytes isolated from 4T1-AdVEGFR2 immunized mice showed an apparent protective antitumor effect, compared with the controls $(\mathrm{P}<0.05)$. (B) The adoptive transfer of sera from mice immunized with 4T1-AdVEGFR2 did not significantly inhibit tumor growth $(\mathrm{P}>0.05)$. Results are expressed as the means \pm SD. Data are representative of two independent experiments.

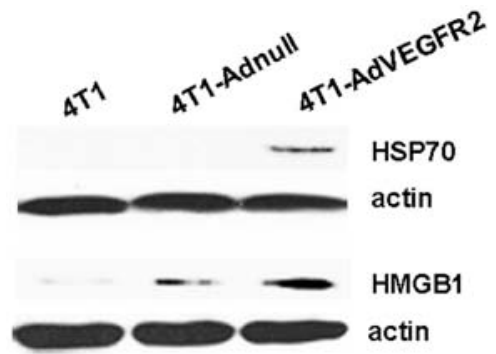

Figure 6. HMGB1 and HSP70 are selectively released by dying tumor cells. HMGB1 and HSP70 were detected by western blot analysis in whole-cell lysates of irradiated 4T1, AdVEGFR2-infected 4T1 and Adnull-infected 4T1 cells. HMGB1 and HSP70 were increased in irradiated AdVEGFR2-infected $4 \mathrm{~T} 1$ cells.

the number of $\mathrm{CD}^{+}$lymphocyte cells was increased $53.4 \%$ in the 4T1-AdVEGFR2-treated group compared with the 4T1-Adnull-treated group (Fig. 4B). These results indicate that both $\mathrm{CD} 4^{+}$and $\mathrm{CD} 8^{+}$lymphocytes are important for the therapeutic activity of the 4T1-AdVEGFR2 vaccine against 4T1 breast tumors. To identify the autoantibodies against $4 \mathrm{~T} 1$ cells within sera from treated mice, we investigated the sera by ELISA. The autoantibodies were increased in the 4T1-AdVEGFR2-treated group $(8566.667 \pm 351.1885 \mathrm{pg} / \mathrm{ml})$ when compared with the control groups $(\mathrm{P}<0.001)$ (Fig. 4C).

Serum and lymphocyte adoptive transfer in vivo. Given that the autoantibodies and $\mathrm{T}$ lymphocytes were increased in the 4T1-AdVEGFR2-treated mouse blood and tumor sections, we sought to investigate the protection from tumor growth of serum and lymphocyte adoptive transfer. As expected, treatment with lymphocytes from the spleens of the mice immunized with the irradiated AdVEGFR2-infected 4T1 cell vaccine resulted in apparent inhibition of tumor growth, compared with those from mice immunized with 4T1-Adnull, 4T1 or NS (Fig. 5A). Yet, the adoptive transfer of sera from mice immunized with 4T1-AdVEGFR2 did not effectively inhibit tumor growth (Fig. 5B). These results indicated that the immune responses to the irradiated AdVEGFR2-infected cell vaccine were mainly cellular immune responses.
Expression of HMGB1 and HSP70 in tumor cells infected with AdVEGFR2. Reportedly, HSP70 and the alarmin highmobility-group box 1 protein (HMGB1) are involved in the activation of tumor antigen-specific T-cell immunity (22-25). Our findings showed that the therapeutic antitumor immunity of the vaccine was mainly cellular immunity. Thus, we investigated the expression of HMGB1 and HSP70 by western blot analysis in whole-cell lysates of irradiated 4T1 tumors infected with AdVEGFR2, Adnull or uninfected. As shown in Fig. 6, the surface expression of HMGB1 and HSP70 in irradiated AdVEGFR2-transfected 4T1 cell tumors was obviously increased, and HSP70 was scarcely expressed in the groups treated with $4 \mathrm{~T} 1$ cells.

\section{Discussion}

In the present study, we demonstrated that the immunotherapy based on the irradiated AdVEGFR2-infected 4T1 cell vaccine had an increased antitumor effect when compared with the irradiated Adnull-infected 4T1 cell or irradiated 4T1 cell vaccines. In vivo, irradiated AdVEGFR2-infected 4T1 cell vaccine significantly prevented local tumor growth and pulmonary metastasis. The autoantibodies against $4 \mathrm{~T} 1$ cells were increased in the vaccine-treated mouse sera, yet the antitumor activity was not caused by the adoptive transfer of sera. Instead, the adoptive transfer of spleen lymphocytes caused an apparent antitumor activity. The number of $\mathrm{CD} 4^{+}$and $\mathrm{CD} 8^{+} \mathrm{T}$ lymphocytes was increased in the tumors treated with the irradiated AdVEGFR2-infected cell vaccine, and angiogenesis was markedly inhibited. The surface exposures of HMGB1 and HSP70 in the 4T1 cells were apparently increased in vitro. The antitumor mechanisms of the vaccine may be due to induction of celluar immunity by targeted inhibition of tumor cells and tumor vessels.

Whole-cell vaccines are characterized by their broad array of tumor-associated antigens $(26,27)$. Vaccination with irradiated tumor cells has been studied in various animal models as early as the 1970s. Yet, tumor cells are not very immunogenic, thus many proteins or cytokines were infected into tumor cells to stimulate immunogenicity. These immunostimulating proteins include B7.1 (CD80), CCL21 and GM-CSF (8-11). 
Reportedly, vaccination with irradiated tumor cells engineered to secrete murine GM-CSF stimulated potent, specific, and long-lasting antitumor immunity (28).

Angiogenesis is important not only for normal embryonic development but also for the development of pathologic conditions such as cancer, retinopathies and rheumatoid arthritis (29-32). There is accumulating evidence that the growth and persistence of solid tumors and their metastasis are angiogenesis-dependent $(14,33,34)$. VEGFR-2 is the main receptor responsible for the angiogenic activity of VEGF. Antiangiogenic therapy targeting VEGFR2 represents a good alternative for the treatment of tumors $(35,36)$. Our previous studies demonstrated that a quail homologous VEGFR2 protein vaccine effectively induced protective and therapeutic antitumor immunity in several solid and hematopoietic tumor models in mice (20), which suggested that VEGFR2 gene therapy warrants further research.

In the present study, 4T1 cells were infected with the VEGFR2 gene, which synchronously stimulating the immune response to tumor cells and tumor vessels. The increase in $\mathrm{CD}^{+}$and $\mathrm{CD}^{+} \mathrm{T}$ lymphocytes in tumors after treatment with the AdVEGFR2-infected cell vaccine showed that cellular immunity was involved in the antitumor immune response, which was further confirmed by the significant inhibition of tumor growth by spleen lymphocyte adoptive transfer. Reportedly, the activation of tumor antigen-specific T-cell immunity involves secretion or surface exposure of the high-mobility-group box 1 (HMGB1) alarmin protein and HSP70 by dying tumor cells (22-25). Our results demonstrated that HMGB1 and HSP70 were upregulated in the irradiated AdVEGFR2-infected 4T1 cells. Thus, cell immunity played an important role in the irradiated infected VEGFR2 wholecell vaccine treatment.

Collectively, our data in the present study suggest that immunotherapy with AdVEGFR2 whole-cell vaccine was effective for therapeutic antitumor immunity in a breast tumor model. This antitumor effect may result from eliciting the host CTL response against 4T1 cells and tumor vessels. These findings may be of importance in further exploration of the potential application of this vaccine in the treatment of breast cancer.

\section{Acknowledgements}

This study was supported by the National Natural Science Foundation of China (30901773).

\section{References}

1. Perez CA, Fu A, Onishko H, Hallahan DE and Geng L: Radiation induces an antitumour immune response to mouse melanoma. Int J Radiat Biol 85: 1126-1136, 2009.

2. Chakravarty PK, Guha C, Alfieri A, et al: Flt3L therapy following localized tumor irradiation generates long-term protective immune response in metastatic lung cancer: its implication in designing a vaccination strategy. Oncology 70: 245-254, 2006.

3. Nakajima K, Yanagawa T, Watanabe $\mathrm{H}$ and Takagishi $\mathrm{K}$ : Hyperthermia reduces migration of osteosarcoma by suppression of autocrine motility factor. Oncol Rep 28: 1953-1958, 2012.

4. Weiss EM, Frey B, Rodel F, et al: Ex vivo- and in vivo-induced dead tumor cells as modulators of antitumor responses. Ann NY Acad Sci 1209: 109-117, 2010.

5. Das A and Ali N: Vaccine prospects of killed but metabolically active Leishmania against visceral leishmaniasis. Expert Rev Vaccines 11: 783-785, 2012.
6. Dols A, Smith JW II, Meijer SL, et al: Vaccination of women with metastatic breast cancer, using a costimulatory gene (CD80)-modified, HLA-A2-matched, allogeneic, breast cancer cell line: clinical and immunological results. Hum Gene Ther 14: 1117-1123, 2003.

7. Riedl K, Baratelli F, Batra RK, et al: Overexpression of CCL-21/secondary lymphoid tissue chemokine in human dendritic cells augments chemotactic activities for lymphocytes and antigen presenting cells. Mol Cancer 2: 35, 2003.

8. Li B, VanRoey M, Wang C, Chen TH, Korman A and Jooss K: Anti-programmed death-1 synergizes with granulocyte macrophage colony-stimulating factor-secreting tumor cell immunotherapy providing therapeutic benefit to mice with established tumors. Clin Cancer Res 15: 1623-1634, 2009.

9. van Elsas A, Hurwitz AA and Allison JP: Combination immunotherapy of B16 melanoma using anti-cy totoxic T lymphocyte-associated antigen 4 (CTLA-4) and granulocyte/macrophage colony-stimulating factor (GM-CSF)-producing vaccines induces rejection of subcutaneous and metastatic tumors accompanied by autoimmune depigmentation. J Exp Med 190: 355-366, 1999.

10. van den Eertwegh AJ, Versluis J, van den Berg HP, et al: Combined immunotherapy with granulocyte-macrophage colony-stimulating factor-transduced allogeneic prostate cancer cells and ipilimumab in patients with metastatic castrationresistant prostate cancer: a phase 1 dose-escalation trial. Lancet Oncol 13: 509-517, 2012.

11. Guckel B, Stumm S, Rentzsch C, Marme A, Mannhardt G and Wallwiener D: A CD80-transfected human breast cancer cell variant induces HER-2/neu-specific T cells in HLA-A*02matched situations in vitro as well as in vivo. Cancer Immunol Immunother 54: 129-140, 2005.

12. Gille H, Kowalski J, Li B, et al: Analysis of biological effects and signaling properties of Flt-1 (VEGFR-1) and KDR (VEGFR-2). A reassessment using novel receptor-specific vascular endothelial growth factor mutants. J Biol Chem 276: 3222-3230, 2001.

13. Zeng H, Dvorak HF and Mukhopadhyay D: Vascular permeability factor (VPF)/vascular endothelial growth factor (VEGF) peceptor-1 down-modulates VPF/VEGF receptor-2-mediated endothelial cell proliferation, but not migration, through phosphatidylinositol 3-kinase-dependent pathways. J Biol Chem 276: 26969-26979, 2001.

14. Takahashi Y, Kitadai Y, Bucana CD, Cleary KR and Ellis LM: Expression of vascular endothelial growth factor and its receptor, KDR, correlates with vascularity, metastasis, and proliferation of human colon cancer. Cancer Res 55: 3964-3968, 1995.

15. Vajkoczy P, Farhadi M, Gaumann A, et al: Microtumor growth initiates angiogenic sprouting with simultaneous expression of VEGF, VEGF receptor-2, and angiopoietin-2. J Clin Invest 109: 777-785, 2002.

16. Breier G, Blum S, Peli J, et al: Transforming growth factor-beta and Ras regulate the VEGF/VEGF-receptor system during tumor angiogenesis. Int J Cancer 97: 142-148, 2002.

17. Prewett M, Huber J, Li Y, et al: Antivascular endothelial growth factor receptor (fetal liver kinase 1) monoclonal antibody inhibits tumor angiogenesis and growth of several mouse and human tumors. Cancer Res 59: 5209-5218, 1999.

18. Wood JM, Bold G, Buchdunger E, et al: PTK787/ZK 222584, a novel and potent inhibitor of vascular endothelial growth factor receptor tyrosine kinases, impairs vascular endothelial growth factor-induced responses and tumor growth after oral administration. Cancer Res 60: 2178-2189, 2000.

19. Thomas AL, Morgan B, Drevs J, et al: Vascular endothelial growth factor receptor tyrosine kinase inhibitors: PTK787/ZK 222584. Semin Oncol 30: 32-38, 2003.

20. Liu JY, Wei YQ, Yang L, et al: Immunotherapy of tumors with vaccine based on quail homologous vascular endothelial growth factor receptor-2. Blood 102: 1815-1823, 2003.

21. Li G, Tian L, Hou JM, et al: Improved therapeutic effectiveness by combining recombinant CXC chemokine ligand 10 with cisplatin in solid tumors. Clin Cancer Res 11: 4217-4224, 2005.

22. Seong SY and Matzinger P: Hydrophobicity: an ancient damageassociated molecular pattern that initiates innate immune responses. Nat Rev Immunol 4: 469-478, 2004.

23. Jiang D, Liang J, Fan J, et al: Regulation of lung injury and repair by Toll-like receptors and hyaluronan. Nat Med 11: 1173-1179, 2005.

24. Tsung A, Sahai R, Tanaka H, et al: The nuclear factor HMGB1 mediates hepatic injury after murine liver ischemia-reperfusion. J Exp Med 201: 1135-1143, 2005. 
25. Apetoh L, Ghiringhelli F, Tesniere A, et al: Toll-like receptor 4-dependent contribution of the immune system to anticancer chemotherapy and radiotherapy. Nat Med 13: 1050-1059, 2007.

26. Soliman H: Developing an effective breast cancer vaccine. Cancer Control 17: 183-190, 2010.

27. Solbrig CM, Saucier-Sawyer JK, Cody V, Saltzman WM and Hanlon DJ: Polymer nanoparticles for immunotherapy from encapsulated tumor-associated antigens and whole tumor cells. Mol Pharm 4: 47-57, 2007.

28. Liu S, Wang H, Yang Z, et al: Enhancement of cancer radiation therapy by use of adenovirus-mediated secretable glucoseregulated protein 94/gp96 expression. Cancer Res 65: 9126-9131, 2005.

29. Shalaby F, Rossant J, Yamaguchi TP, et al: Failure of bloodisland formation and vasculogenesis in Flk-1-deficient mice. Nature 376: 62-66, 1995.

30. Wei YQ, Wang QR, Zhao X, et al: Immunotherapy of tumors with xenogeneic endothelial cells as a vaccine. Nat Med 6: 1160-1166, 2000 .
31. Pe'er J, Shweiki D, Itin A, Hemo I, Gnessin H and Keshet E: Hypoxia-induced expression of vascular endothelial growth factor by retinal cells is a common factor in neovascularizing ocular diseases. Lab Invest 72: 638-645, 1995.

32. Plate KH, Breier G, Weich HA and Risau W: Vascular endothelial growth factor is a potential tumour angiogenesis factor in human gliomas in vivo. Nature 359: 845-848, 1992.

33. Folkman $\mathrm{J}$ : What is the evidence that tumors are angiogenesis dependent? J Natl Cancer Inst 82: 4-6, 1990.

34. Fine BA, Valente PT, Feinstein GI and Dey T: VEGF, flt-1, and $\mathrm{KDR} / \mathrm{flk}-1$ as prognostic indicators in endometrial carcinoma. Gynecol Oncol 76: 33-39, 2000.

35. Fidler IJ and Ellis LM: The implications of angiogenesis for the biology and therapy of cancer metastasis. Cell 79: 185-188, 1994.

36. Yancopoulos GD, Klagsbrun M and Folkman J: Vasculogenesis, angiogenesis, and growth factors: ephrins enter the fray at the border. Cell 93: 661-664, 1998. 